COMO SER UM NEGRO

\author{
Marcelo Ariel $^{1}$
}

\title{
Poema
}

Começamos no presente atemporal eu e o mundo que é uma mentira porque a própria eternidade finge morrer em nós

como é que algo pode realmente existir se a eternidade não teve começo nem fim aviso aos navegantes não irei usar aqui nenhum acento apenas virgulas e traços aleatórios como o dia e a noite, estes sonhos, os verdadeiros dias e noites são sem fronteiras e fora do tempo e nunca aconteceram

O que está atrás do pensamento é uma vírgula nas frases do mundo podemos usar estas frases de efeito como o ar usa uma carcaça uma cultura de carcaças dissolvida pela luz que é a única coisa

intraduzível

ela e as correntes corrente sanguínea corrente elétrica correntezas

O anjo disse: os cinco sentidos

não tem sentido nem direção

a imanência é um perfume fotografado no riso da caveira

Ozymandias

só existe uma caveira formada por todas as caveiras

${ }^{1}$ Poeta. 


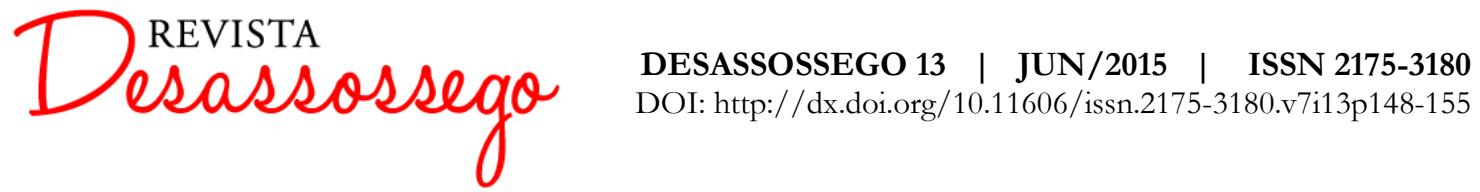

só existe uma rosa formada por todas as rosas

onde você tentou estar

a rosa negra

multiplicada pela matéria escura

isto deveria se chamar nascer

nascer ou se dizer

os três cérebros

não posso com a linearidade

ela é a língua da extinção

Marcelo tem quatro anos

e entra em qualquer casa qualquer mulher é sua mãe

o mundo em sua infanceanoessencialidade

no sobrenatural: eis onde realmente começamos

a vida é essa outra vida

nenhuma palavra vai entrar

nela

nenhuma divisão

nenhuma dicotomia

nenhum dualismo

O sono da linguagem

O lugar se chama Sete anos, o asteroide se chama 


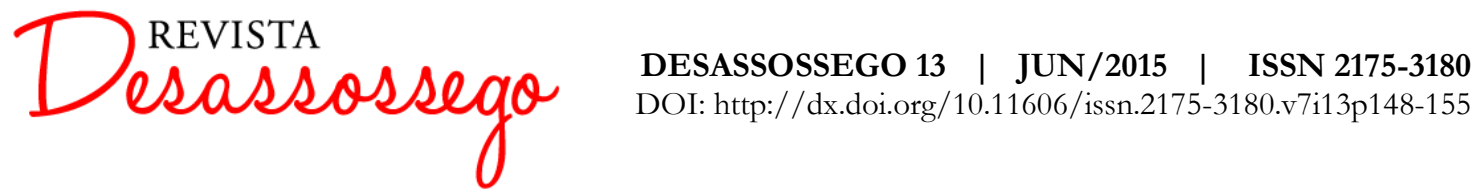

Agora e rege a aparição dos postes batendo em nossa cabeça

A morte é o instante-já congelado, o tempo é o instante-já derretendo do IcebergEternidade

as bombas de nêutrons no mar de neutrinos

imune nos setes anos

O pólen negro descolando da Flor do Eterno

no transe do vento para os campos do interexterno

depois desenvolvi um comportamento cênico

por desconfiança

do mundo

onde não há vida

estamos nele para que ele conheça a vida

memória gravada nas coisas

desconfiança do mundo criado pelas palavras

desconfiança do mundo criado máscaras

desconfiança do mundo encoberto pelas capas

Assim jamais será

Entre no paradoxo

do túnel fora do feminino infinito

saudade do feminino infinito

Myriam ou Eva são o Angélico 


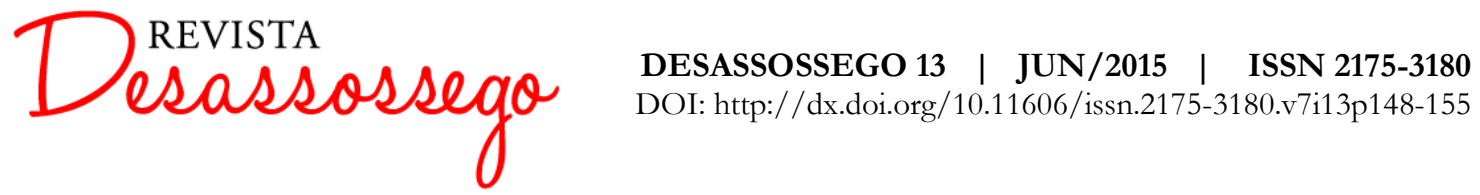

Aqui fora lentamente me transformo em um vapor cênico girando em torno do inalcançável

empenhado em expor

sempre para si mesmo

uma esterilidade

facilmente adquirida

graças ao senso comum

caminho pelas ruas de cabeça baixa

como a maioria dos moradores de Cubatão

com uma fidelidade essencial

ao próprio obscurecimento

com uma camada enfraquecida de autodefesa

por dentro do cinza do ar

sou alguém que se descobre

infindavelmente negro ou seja

que descobre sua singularidade

seu pacto com a matéria escura

como uma matiz escura

da energia luminosa

e além desta destinação

tenho um outro acordo interno 


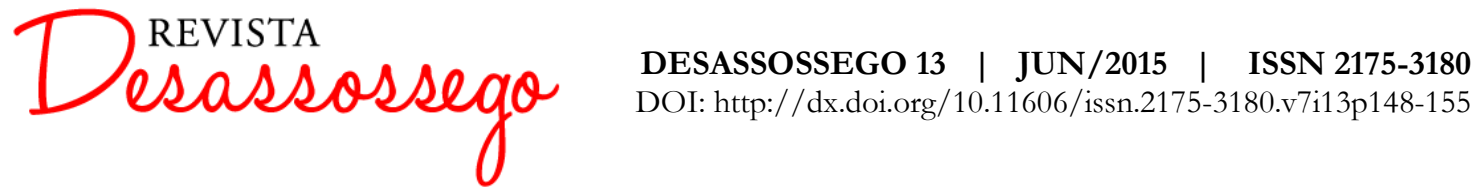

com a invisibilidade, mas não com a nulidade

por isso este livro

dito isto

\section{COMO SER UM NEGRO}

começa

tenho 09 anos

costumo ser

convocado para comprar cigarros nas padarias para as ondinas do puteiro

esta situação vêm da Fenícia ou do Egito

Não aprendemos a ler e escrever na escola

Foi a vizinha

a negra Dona Marlene que me ensinou

quando cheguei no sistema escolar

aprendi que um avanço para nós

é visto como um ousado atraso

por muitos

o senso comum 
é regido pela perda de tempo

em nós há um Pássaro

que jamais canta

por isso jamais saberemos nosso verdadeiro nome

Um pássaro transparente

E um pensamento jamais pronunciado que é como uma libélula

Aos 09 anos aprendemos a jamais pronunciar o nome desse silêncio

Ensurdecedor, quis dizer, desse pensamento enlouquecedor

aprendi a dizer sempre outra coisa

a perder por delicadeza parte do aprendizado

sobre o Sol

chamado

NÃO

Negro é um lugar ôntico

e Preto é um lugar social

soube desde sempre

que o ôntico

e o social

nunca se encontram 


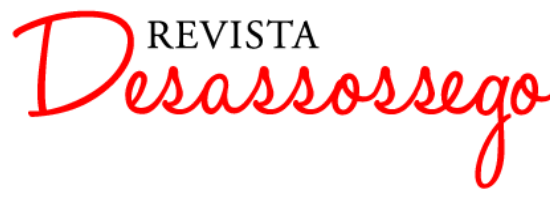

no mesmo plano dimensional

soube desde sempre

que a dimensão em que me movia e respirava

\title{
era a dimensão do nunca
}

\author{
A inexistente \\ O imperador do sorvete me diz que a humanidade profunda habita sempre a \\ dimensão do nunca, que no presente a Terra é desabitada e pertence aos pássaros, \\ insetos e árvores \\ E que existe a construção de um poema supremo na manutenção de nossa ausência \\ O desejo coletivo que se manifesta pela destruição e obstrução de algumas \\ destinações sublimes que incluem a DESTINAÇÃO NEGRO ÍNDIO o mundo dos \\ pássaros- árvores
}

a viagem dentro do temporal estava nos nossos 09 anos dentro dos 07 anos dentro do Pólen Negro

que é uma parte da matéria escura

o tempo exterior nunca será um poema

\section{sussurrava o anjo da História}

promovendo este movimento que nunca será para a frente

como imaginávamos

mas para as origens, para o terror de antes da ausência

que neste momento que estamos vivendo agora 


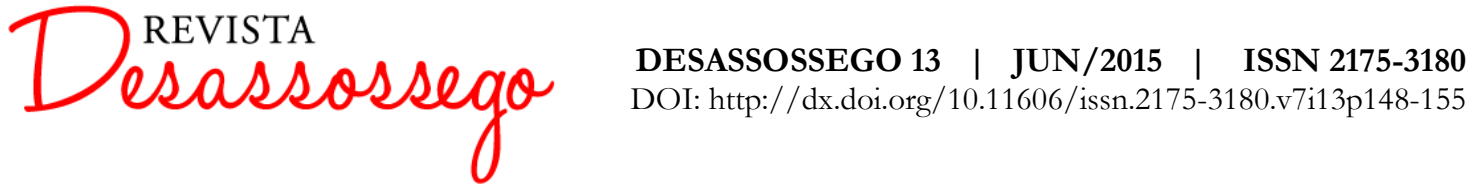

se confunde com o esquecimento do nome do primeiro negro a chegar aqui

para morrer

longe de seu DESTINO de pássaro-árvore

como nós

ou seja LONGE DO INFINITO EXTERIOR 